\title{
Development of Multiple New 120 kV Transmission Electron Microscope Configurations Applicable for a Wide Range of Fields
}

\author{
K. Tamura ${ }^{1}$, T. Fujii ${ }^{1}$, H. Mise ${ }^{2}$, I. Nagaoki ${ }^{1}$, K. Kageyama ${ }^{2}$, A. Wakui ${ }^{3}$, M. Shirai $^{3}$, H. Matsumoto $^{3}$, \\ M. Konomi ${ }^{4}$, and T. Yaguchi ${ }^{1}$ \\ 1. Electron Microscope System Design 2nd Dept., Hitachi High-Technologies Corporation, Ibaraki, \\ JAPAN. \\ 2. Electron Microscope Solution Systems Design Dept., Hitachi High-Technologies Corporation, Ibaraki, \\ JAPAN. \\ 3. Application Development Dept., Hitachi High-Technologies Corporation, Ibaraki, JAPAN. \\ 4. Marketing Dept., Hitachi High-Technologies Corporation, Tokyo, JAPAN
}

Hitachi has developed two new types of $120 \mathrm{kV}$ transmission electron microscopes (TEMs) to meet various needs of users and observe specimens ranging from biomedical to material science. The external view of the newly designed TEM which encompasses both configurations is shown in Fig. 1.

Improvement of image contrast and reduction in electron beam irradiation damage are especially important for observing low contrast and beam-sensitive biological specimens. One configuration for this novel TEM configuration has the ability to easily observe low contrast specimens by utilizing an objective lens with a long focal length and therefore high-contrast. The TEM observation, with high scattering contrast, is realized by equipping a combination of a specially designed objective lens and a small objective aperture to provide a small scattering angle of transmitted electrons optimal for formation of such image. Figure 2 demonstrates an unstained, very low contrast mouse kidney section. To address such samples, a high-sensitivity CMOS camera has been equipped to make observation possible and provide easy navigation with low electron beam irradiation.

System software of the TEM has also been improved. The graphical user interface of the newly developed software allows novice and advanced users alike to operate the instrument with ease. Additionally, the new software function of TEM image navigation has been greatly advanced for whole grid search functionality.

The second new $120 \mathrm{kV}$ TEM design is equipped with a high-resolution objective lens [1] which has a short focal length and is designed primarily for observation of nanomaterials / material science. A single-crystal $\mathrm{LaB}_{6}$ cathode is used as an electron source and therefore encompasses high brightness capable of TEM observation at high magnification. This new $120 \mathrm{kV}$ HR-TEM provides on-axis lattice resolution of $0.19 \mathrm{~nm}$. Figure 3 shows a TEM image of Si (100) obtained with this configuration. An automated operation for acquiring the selected-area electron diffraction (SAED) patterns at the plural positions is available [2].

STEM images of electro catalyst of fuel cell captured by the new $120 \mathrm{kV} \mathrm{HR-TEM} \mathrm{with} \mathrm{a} \mathrm{LaB}_{6}$ cathode are shown in Fig. 4. A distribution of metal particulates is clearly observed and the STEM image resolution at $120 \mathrm{kV}$ is $1 \mathrm{~nm}$. A large-size $\left(100 \mathrm{~mm}^{2}\right)$ energy dispersive X-ray (EDX) analyzer can also be equipped for high-sensitivity element composition analysis. 


\section{References:}

[1] Kubo, T. et al, Microsc. Microanal. 19 (Suppl 2) (2013) p. 1328.

[2] Kamino T. et al, Proc. of IMC 18, Prague, Czech Republic (2014) IT-6-P-1552.

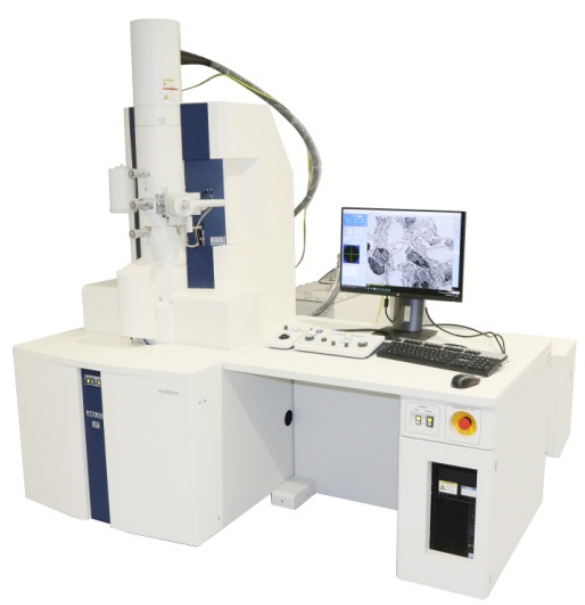

Figure 1. The newly designed Hitachi Transmission Electron Microscope.

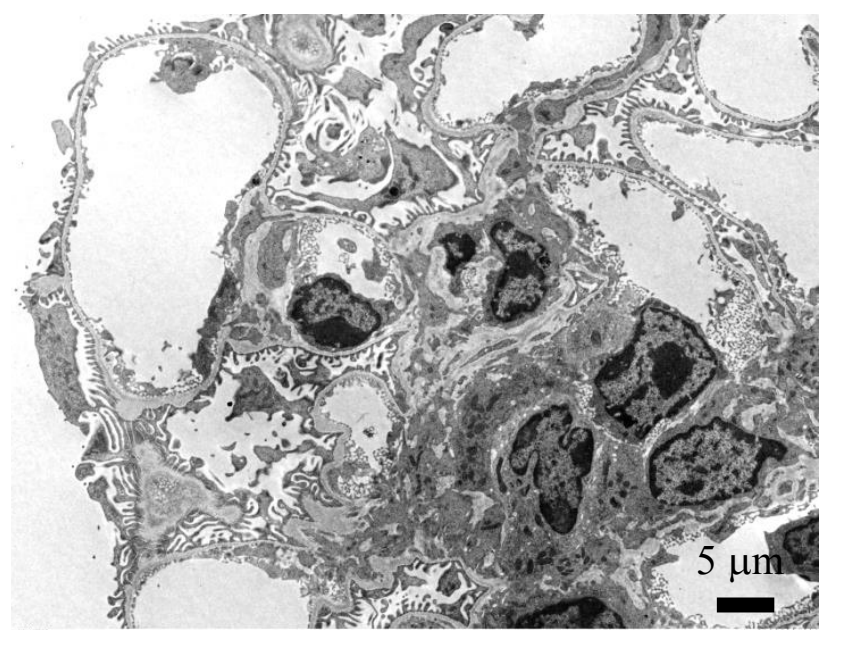

Figure 2. TEM image of mouse kidney (unstained section) obtained by the new $120 \mathrm{kV}$ TEM (high contrast type) for the biomedical field. Acceleration voltage is $80 \mathrm{kV}$.



Figure 3. TEM image of $\mathrm{Si}(100)$ with the new $120 \mathrm{kV}$ TEM (high resolution type) for the material field. Acceleration voltage is 120 $\mathrm{kV}$.
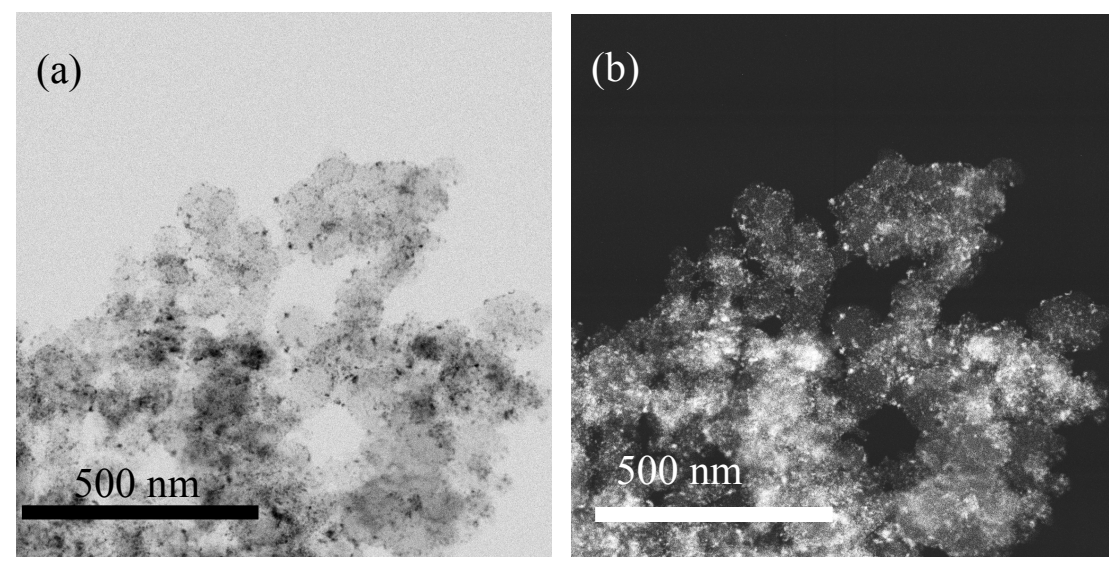

Figure 4. STEM image of materials for a fuel cell with the new $120 \mathrm{kV}$ TEM (high resolution type). (a): bright field image, (b): dark field image 